\title{
PERCEPÇÃO DE ESTUDANTES DO ENSINO MÉDIO DE ESCOLAS PÚBLICAS SOBRE COMPREENSÃO LEITORA
}

\author{
PERCEPTION OF HIGH SCHOOL STUDENTS OF PUBLIC SCHOOLS ABOUT \\ READING COMPREHENSION
}

\author{
Jonaso José dos Passos Dias ${ }^{1}$ \\ Janari da Silva Pedroso ${ }^{2}$
}

RESUMO: A leitura é um processo cada vez mais presente no cotidiano do ser humano e possibilita a inserção social, entretanto o ato de ler não finaliza na simples decodificação da palavra ou da linguagem escrita, ler é questionar o que está escrito num texto. Diante da situação enfrentada pelo sistema educacional no que condiz à dificuldade do ensino e aprendizagem da leitura, este artigo objetiva averiguar a percepção sobre compreensão leitora em estudantes do terceiro ano do ensino médio por meio de entrevista e entender, sob a ótica destes sujeitos, que tipo de leitura é mais agradável para se trabalhar em sala de aula, qual a que compõe significado para a formação do indivíduo e se enfrentam dificuldades de compreensão textual, quais as que impõem barreiras para o entendimento de leitura. $\mathrm{O}$ estudo foi realizado por meio da abordagem qualitativa a qual possibilitou a construção de dados que permitiram uma análise semântico-temática do conteúdo abordado. As análises possibilitaram discussões sobre atividades que abordam a respeito da leitura e compreensão leitora. Por fim, os resultados deste estudo mostraram que estudantes das séries finais do ensino médio encontram dificuldade de compreenderem um texto por conta de este ser trabalhado descontextualizado da vivência atual dos estudantes

\footnotetext{
${ }^{1}$ Formado em Licenciatura Plena em Letras pela Universidade Federal do Pará; Pós-graduado em nível de Especialização em Literatura Brasileira pela Universidade Luterana do Brasil; Mestre em Educação pela Universidade de Los Pueblos da Europa- Espanha; Mestre em Psicologia pela Universidade Federal do Pará UFPA; Doutorando em Educação pela Universidade Luterana do Brasil-ULBRA. Possui experiência na área de docência em Letras, com ênfase em Língua Portuguesa e Literatura. http://lattes.cnpq.br/2891582673444698. ORCID https://orcid.org/oooo-ooo-4429-o84X. E-mail: jonasodias@rede.ulbra.br

${ }^{2}$ Bolsista Produtividade do CNPq (Nível 2). Coordenador do Laboratório de Desenvolvimento e Saúde (LADS) http://lads.ufpa.br/. Editor Associado da Revista Psicologia: Teoria e Pesquisa Docente no Programa de Pós-Graduação em Teoria e Pesquisa do Comportamento (PPGTPC). Docente no Programa de Pós-Graduação em Psicologia (PPGP)Universidade Federal do Pará-Belém, Pa,Brasil. Lattes: http://lattes.cnpq.br/4096274367867186. http://orcid.org/oooo-ooor-7602-834XWeb of Science Researcher ID F-6950-2014https://publons.com/researcher/1737679/janari-da-silva-pedroso/

www.scopus.com/authid/detail.uri?authorId=57192193063. E-mail: pedrosoufpa@gmail.com.
} 
no que diz respeito à linguagem, a temática abordada, assim como a importância do conteúdo para a vida.

Palavras-chaves: Leitura. Compreensão. Análise de conteúdo.

ABSTRACT: Reading is a process increasingly present in the daily lives of human beings and enables social inclusion, however the act of reading does not end with the simple decoding of the word or written language, reading is questioning what is written in a text. Given the situation faced by the educational system regarding the difficulty of teaching and learning to read, this article aims to investigate the perception of reading comprehension in third-year high school students through interviews and understand, from the perspective of these subjects, that type of reading is more pleasant to work in the classroom, which one makes up meaning for the individual's formation and if they face difficulties in textual comprehension, which ones impose barriers to the understanding of reading. The study was carried out using a qualitative approach, which enabled the construction of data that allowed a semantic-thematic analysis of the content addressed. The analyzes enabled discussions on activities that address reading and reading comprehension. Finally, the results of this study showed that students in the final grades of high school find it difficult to understand a text because it is worked out of context from the current experience of students with regard to language, the topic addressed, as well as the importance of content for life.

Keywords: Reading. Understanding. Content analysis.

\section{INTRODUÇÃO}

Este estudo foi desenvolvido por meio de averiguação da percepção da compreensão leitora em alunos do terceiro ano do Ensino Médio em escolas públicas estaduais no município de Oriximiná, no estado do Pará por meio da abordagem qualitativa.

Neste sentido, primeiramente foram realizados estudos que perpassaram pelo entendimento da linguagem como meio de comunicação, o pensamento relacionado à linguagem, a leitura e os modos de compreensão, assim com as dificuldades de entendimento. Em seguida foi aplicada a entrevista nos sujeitos participantes da pesquisa com o intuito de coletar dados para que fossem posteriormente trabalhados na análise do conteúdo. 
A linguagem, funcionalmente, objetiva a comunicação, logo pode ser socialmente construída e difundida num determinado espaço social. Como meio de comunicação deve expressar enunciado que favoreçam a compreensão, pois a expressão e o entendimento deste coadunam com funções de comunicação e de pensamento (VIGOTSKY, 200I).

A leitura permite não só o exercício do poder individual de análise como a tomada de decisão. Possibilita também um entendimento amplo da realidade e exige um aprendizado contínuo para que se alcance resultados na assimilação de um conhecimento lido. Logo, a compreensão da leitura é fundamental para o indivíduo estabelecer uma relação coerente com a realidade em que está inserido (OLIVEIRA; BORUCHOVITCH; SANTOS, 2007).

Sobre a compreensão da leitura em discentes, percebe-se que alguns aprenderão a ler e não encontrarão nenhum problema com o método utilizado, mas alguns necessitarão de ajuda especial para conseguir sucesso na mesma atividade (ZUCOLOTO, 200I).

Os modos de compreensão da leitura em sala de aula estão em contraposição a uma concepção que ressalta a literariedade do texto e a singularidade do sentido. A compreensão é entendida como um processo dialógico que pode ser compartilhado que produz, cria e completa sentidos (SILVA, 1998). Logo, a compreensão da leitura não consiste somente no reconhecimento das características internas de um texto, mas deve-se levar em consideração a contextualidade que a temática aborda e a intertextualidade que o texto pode oferecer.

Do modo como é tratado por Vigotsky (1989), o sujeito não é apenas ativo, mas interativo nas suas relações. Por isso, torna-se necessário conhecer tais fundamentos que servirão de base a esta pesquisa, no que concerne ao entendimento das relações interpessoais que o aluno possui e, por meio deste, compreender $e$ interpretar as dificuldades de aprendizado da leitura.

Vigotsky (1988) não nega que exista diferença entre os indivíduos, que uns estejam predispostos a algumas atividades do que outros, em razão do fator físico ou genético. Entretanto, não concebe que esta diferença seja fundamental para a 
aprendizagem, pois para o teórico o sujeito realiza uma atividade organizadora na sua interação com o mundo e é capaz, inclusive, de renovar a própria cultura.

As interações contextuais permitem ao sujeito ultrapassar a impressão inicial das ideias surgidas e favorecem conhecimentos que vão além das impressões primárias sobre o objeto e, com isso se produz informações sistematizadas que instrumentalizam um exame concreto da realidade interagida (MARTINS, 2009).

Os objetos relacionados à atividade produtiva do ser humano dependem de elementos que mediam a ação e os resultados delas obtidos, por isso, as atividades mediadas, no caso o processo de ensino e aprendizagem, devem ser facilitados por meio de técnicas interativas que ampliam as possibilidades do sujeito de produzir conhecimentos significantes para sua formação (SILVA, 2010).

Com base nesses indicativos teóricos, decidiu-se aprofundar nesta temática por verificar, enquanto docente da área de Letras há mais de vinte anos, que discentes do Ensino Médio encontram dificuldade em ler e efetivar a compreensão de textos, ou seja, apenas decodificam os códigos linguísticos.

Por isso, foi realizado este estudo a fim de conhecer sobre o que os sujeitos pensam a respeito de atividades desenvolvidas em sala de aula sobre o ensino da leitura, entender os motivos que levam os estudantes a terem problemas de assimilação e saber se o conhecimento adquirido por meio desta é importante na realidade em que vivem.

Acredita-se que esta investigação proporcionará subsídios importantes para se esclarecer algumas das questões mencionadas acima sobre problemas que alunos possuem em proferir uma leitura e assimilar a compreensão de um texto. Espera-se também que o resultado deste material que foi investigado possa ser significativo para estudos posteriores que enfatizem o tema leitura, e com a soma destas pesquisas, construa-se respostas a este problema.

\section{METODOLOGIA}

O estudo foi realizado por meio da análise do conteúdo expresso na linguagem verbal, abstraído por uma entrevista, o qual possibilitou a compreensão da ótica dos 
sujeitos sobre o tema abordado, o que caracteriza o estudo qualitativo que objetivou entender, segundo a opinião dos sujeitos, o que causam as possíveis dificuldades de leitura.

O local onde se realizou a pesquisa foi em instituições de ensino localizadas no município de Oriximiná - Pará, e são as únicas que pertencem à rede estadual de Ensino e funcionam especificamente com o Ensino Médio. Ressalta-se que a escolha destas unidades, assim como o município mencionado, deu-se por conta deste pesquisador conviver nesta localidade e por ser educador da área de Letras no Ensino Médio.

A pesquisa de campo foi realizada de maio a junho de 2012. Algumas providências foram tomadas a fim de que o esclarecimento da pesquisa, as etapas e métodos de divulgação fossem compreendidos pelos sujeitos participantes,

Assim, este projeto foi submetido e aprovado com a carta de número $007 / 12$ pelo Comitê de Ética do Instituto de Ciências da Saúde da Universidade Federal do Pará, parecer $\mathrm{n}^{\mathrm{0}}$ 020/12 - ICS/UFPA do município de Belém, conforme o que prescreve a Resolução 1996/96 (BRASIL, 1996), que trata dos parâmetros sobre pesquisa que envolve seres humanos, pois foram definidos os procedimentos necessários para a realização da pesquisa, tais como: explicitar o que é a pesquisa, o pesquisador responsável, os riscos e benefícios que envolvem a análise, a relevância social da mesma, assim como a preservação da identidade de cada participante.

Os alunos tiveram a opção de escolha para participarem ou não deste estudo, e a decisão de participação foi referendada por um documento que se denomina de Termo de Consentimento Livre e Esclarecido que foi assinado pelos alunos maiores de idade e os menores de idade, foram assinados pelos pais ou responsáveis. $O$ documento foi antes submetido ao Comitê de Ética em Pesquisa em Seres Humanos e aprovado.

2. I Estudo qualitativo

A abordagem qualitativa é um importante referencial metodológico para a pesquisa em educação. Isso significa dizer que, no campo educacional, a pesquisa de caráter qualitativo busca compreender os diversos elementos dos fenômenos estudados. Assim, por essa abordagem os fenômenos educacionais são entendidos a partir de sua complexidade histórica, política, social e cultural (FLICK, 2006). 
Participaram 36 (trinta e seis) alunos da entrevista sendo i6 da escola A e 20 da escola B. Foram incluídos os 177 (cento e setenta e sete) alunos do terceiro ano médio turno da manhã das escolas A e B que consentiram participar voluntariamente da pesquisa e sorteados 36 (trinta seis) para a entrevista. Por outro lado, foram excluídos da entrevista os alunos que não foram sorteados ou que se recusaram a assinar o TCLE.

Nesta pesquisa, foi utilizada a entrevista semipadronizada ou semiestruturada em virtude de adequar-se aos objetivos deste estudo. Logo, por meio deste instrumento foram formatadas basicamente três indagações que dizem respeito a situações que podem estar dificultando o aprendizado da leitura de textos em sala de aula, o tipo de texto que desperta interesse e qual o sentido que a leitura pode trazer para as vidas dos alunos.

As transcrições das entrevistas realizadas foram analisadas com base no método da Análise de Conteúdo e considerados, não apenas a semântica das expressões, mas também a interpretação do sentido que o indivíduo atribui às mensagens, pois se entende que este problema necessita de óticas diferenciadas (BARDIN, 2009).

Neste estudo, a análise de conteúdo seguiu o critério semântico-temático de categorização, por considerá-los apropriados aos objetivos aqui propostos, pois por meio desta análise foram propiciados meios de se compreender o material textual e que forneceu condições de abstrair elementos que proporcionou entendimento da mensagem comunicada e favoreceu a criação das categorias a posteriori em função das indagações de pesquisa que se pretendia elucidar.

Portanto, por meio da análise de conteúdo se analisou os sentidos e os significados das mensagens comunicadas. Assim, a pré-análise, a exploração do material obtido das entrevistas transcritas, a codificação em unidades de registro e de contexto seguidas da organização de categorias molares e moleculares é que permitiram a compreensão das dificuldades envolvidas na habilidade leitora de alunos do terceiro ano do ensino médio de escolas públicas da cidade de Oriximiná. 


\section{2 PROCEDIMENTOS}

Foi realizado contato com a direção das escolas, locais escolhidos para a pesquisa, a fim de obter autorização para realização e adesão ao projeto. Em seguida, se obtiveram a listagem dos alunos matriculados no terceiro ano do ensino médio no turno da manhã de ambas as escolas.

Foram selecionados por sorteio, a partir da amostra inicial, uma sub-amostra de conveniência de 36 alunos (20\%), sendo i6 alunos da Escola A e 20 alunos da Escola B, respeitando a proporcionalidade dos estratos de cada escola. As entrevistas semiestruturadas foram aplicadas paulatinamente, de acordo com agendamento do pesquisador e disponibilidade dos alunos, foram gravadas e transcritas para posterior análise. Por fim, foi realizado o processo de análise das coletas de dados reunidas pelos instrumentos aplicados, organizados os resultados e feitas discussões sobre os mesmos.

\section{RESULTADOS E DISCUSSÕES}

Para a análise dos dados coletados por meio da entrevista foi utilizado o método de análise de conteúdo, proposto por Bardin (2009). Esse método consiste em um conjunto de técnicas de análise por meio das quais se absorve o conteúdo e indicadores que permitem a inferência dos dados das mensagens captadas.

No processo de interpretação dos dados coletados construíram-se categorias de análise molares e moleculares. As categorias molares são as de maior amplitude. Em conformidade com o Dicionário Técnico de Psicologia (2006), as categorias molares são conceitos vastos e compreensivos em sua natureza do que os conceitos derivados do estudo de unidades menores.

Neste estudo, a análise e interpretações dos dados coletados foram organizadas em duas categorias molares: problemas de leitura e significado e importância da leitura. $\mathrm{Na}$ construção das categorias molares foram percebidas diferenças e particularidades em cada uma das entrevistas. Essas particularidades deram origem às categorias moleculares que foram elaboradas a partir daquilo que se diferenciava em cada relato.

3. I Problema de leitura 
Os Parâmetros Curriculares Nacionais de Língua Portuguesa - PCNLPenfatizam que a leitura constitui um dos principais conteúdo do currículo escolar brasileiro. Por sua vez, os Parâmetros Curriculares Nacionais - PCN/MEC- assinalam que o aluno, ao concluir o ensino médio, deveria apresentar uma leitura proficiente, o que se manifestaria na compreensão do conteúdo lido. Todavia, dados do INEP (2009) evidenciaram que estudantes do ensino médio demonstraram pouco domínio dessa habilidade (OLIVEIRA, 20II).

$\mathrm{Na}$ realidade brasileira, estudantes que demonstram dificuldade para ler e escrever, no sistema público educacional, têm um percurso de aprendizado inadequado, por fatores ligados a condição de letramento dos pais, despreparo do professor, até a adequação dos instrumentos utilizados ao ensino aprendizagem. Logo, a condição leitora é medida por meio de informações sobre a capacidade de decodificar, compreender e correlacionar habilidades às instâncias do cognitivo que levam a compreensão (NASCIMENTO, 20II).

As dificuldades de leitura impedem o progresso educacional em diversas áreas de ensino, pois ela configura-se como via de acesso para as diversas informações repassadas no processo de ensino e aprendizagem de conhecimentos escolares e conhecimentos do mundo (DOCKRELL, 200o).

As dificuldades de compreensão em leitura, hodiernamente, são consideradas problemas de ensino aprendizagem da leitura e dificilmente problema de desenvolvimento de capacidades cognitivas e de conhecimentos, entretanto não se deve desconsiderar que questões como a faixa etária, situação sociocultural, e formas de intervenção também influenciam nos resultados das performances de estudantes (MOUSINHO, 2008).

No ano final do ensino médio é desejável que o estudante domine a compreensão em leitura e demonstre articulação, fluência, análise crítica e criativa das informações. Por outro lado, a falta de proficiência pode produzir uma formação deficitária, e consequentemente o estudante poderá ter dificuldade para compreender informações dos conteúdos técnicos inerentes à formação que almeja ao pleitear o ensino superior (OLIVEIRA, 20II). 
Associar leitura à prática social significa dizer, minimamente, que ela ocorre segundo um objetivo individual e socialmente determinado. Toda leitura, então, pressupõe a atribuição de uma intencionalidade que é variável conforme os objetivos dos leitores, o ambiente e o modo como se realiza a leitura (SANTOS, 1990).

Desse modo, a reconstrução de sentidos da leitura ocorre pela presença de outras vozes, o que implica o conceito de compreensão, pois intervir nas palavras do autor, narrador com outras palavras configuram a formatação de processo compreensivo do que se lê. E, quanto numerosas e substanciais forem, reais serão as compreensões (BAKHTIN, 1995).

Os dados coletados evidenciaram que entrevistados possuem problemas que dificultam a assimilação da leitura e mencionaram que textos com palavras complexas de significados desconhecidos, e também, os ruídos dificultam a compreensão na hora da leitura. Algumas frases que exemplificam estas percepções podem ser observadas no quadro $\mathrm{I}$.

Quadro I- Situações indicadas pelos alunos sobre o problema de leitura

\begin{tabular}{|c|c|c|}
\hline Categoria molar & Categoria molecular & Unidade de registro \\
\hline \multirow{6}{*}{ PROBLEMA DE LEITURA } & \multirow{3}{*}{$\begin{array}{l}\text { DIFICULDADE DE } \\
\text { COMPREENSÃO DO } \\
\text { SIGNIFICADO DAS } \\
\text { PALAVRAS }\end{array}$} & $\begin{array}{l}\text {-"quando o professor apresenta textos com } \\
\text { palavras de significados diferentes". }\end{array}$ \\
\hline & & $\begin{array}{l}\text {-"alguns textos que tem palavras mais } \\
\text { complicadas". }\end{array}$ \\
\hline & & $\begin{array}{l}\text {-"principalmente quando nos dão textos } \\
\text { com palavras difíceis". }\end{array}$ \\
\hline & \multirow{3}{*}{$\begin{array}{l}\text { PROBLEMA DE } \\
\text { CONCENTRAÇÃO }\end{array}$} & $\begin{array}{l}\text { "“O barulho em sala de aula, às vezes } \\
\text { impõe certa dificuldade". }\end{array}$ \\
\hline & & $\begin{array}{l}\text { "A conversa em sala de aula prejudica } \\
\text { nossa concentração." }\end{array}$ \\
\hline & & $\begin{array}{l}\text { "“O barulho na sala de aula, pois para } \\
\text { entender um texto precisamos de } \\
\text { concentração". }\end{array}$ \\
\hline
\end{tabular}

Em relação à categoria molecular que menciona que um dos problemas de leitura é ocasionado por ruídos em sala de aula que prejudicam a concentração, percebe-se que um número significativo de estudantes citou esta dificuldade. Entretanto, o que se percebeu é 
que o problema de concentração ocorre devido a não familiaridade com o texto, com as palavras.

O conhecimento prévio é definido geralmente como o conjunto de saberes que a pessoa traz como contribuição à sua própria leitura. Estes saberes provêm do fluxo informativo que cada pessoa recebe no convívio com os demais membros de uma comunidade social e que no momento em que são acionados por um estímulo, externam em forma de comportamento (GERHARDT; ALBUQUERQUE, 2009).

A concepção construtivista menciona que os conhecimentos prévios que os estudantes possuem sobre o conteúdo proposto a aprender abrangem informações que de maneira direta ou indireta mantém relação ou podem relacionar-se com eles, e estes preceitos justificam a necessidade de considerar num processo de ensino e aprendizagem o conhecimento trazido pelos estudantes de seus ambientes de convívio (CÉZAR COOL, 2009).

Os alunos não são indivíduos abstratos que competem em condições na escola, mas atores socialmente constituídos que trazem consigo informações diferenciadas e, de acordo com este conhecimento distinguido, o desenvolvimento nas atividades escolares reflete um pouco esta desigualdade de oportunidades (NOGUEIRA, 2002).

$O$ que se percebeu é que os estudantes que mencionaram problema de concentração não possuem conhecimento prévio do sentido de alguns vocábulos do sistema linguístico da língua portuguesa, logo desviam o problema de leitura para situações externas, como o barulho, os ruídos produzidos dentro e fora da sala de aula.

Uma aprendizagem se torna significativa quanto mais relação com sentido o aluno for capaz de estabelecer entre os conhecimentos prévios e o novo conhecimento que lhe é apresentado, pois as habilidades construtivas do indivíduo estabelecerão a relação entre as informações obtidas com as que se pretende obter (CÉZAR COOL, 2009).

O conhecimento prévio em leitura pode ser medido por meio de um esquema de estruturas de saber acumulado que se constroem ao longo da vida e que estão ligadas às expectativas sobre os conteúdos dos textos que se lê por meio de pistas oferecidas pelo material linguístico-textual (LEFFA, 1996). 
Logo, a má concentração do estudante pode estar relacionada às dificuldades deste estabelecer a relação de sentido entre o conhecimento trazido de seu ambiente familiar com o novo conhecimento oferecido na instituição de ensino. E, foi mencionando pelos entrevistados que esta situação está relacionada à dificuldade de compreensão do significado das palavras.

Cada indivíduo passa a ser caracterizado pelas informações legadas dos processos interativos do convívio social. Esse conhecimento inclui componentes externos ao indivíduo, e que podem ser postos a serviço do sucesso escolar, pois as habilidades adquiridas podem ser absorvidas no contexto escolar e servir de norte de aprendizagem (NOGUEIRA, 2002).

No que tange à dificuldade de compreensão do sentido das palavras, menciona-se que a carência de outro produzir sentidos e formas de se compreender o mundo a partir da linguagem, torna-se uma necessidade, pois o ato de compreensão propicia a escrita de um texto, com novos significados (SCORSOLINI-COMIN; SANTOS, 2oro). Logo, percebeu-se que estudantes ainda se encontram na fase da indicação de sentidos e significados.

Os problemas de leitura não estão somente em um processo mental de apreensão e de compreensão de conteúdo. O leitor realiza atividades de interpretação e de produção de sentidos. Está também na deficiência de informação cultural, já que a leitura resulta da interação entre pistas linguísticas e conhecimento prévio do leitor (CASTRO, 2008). De acordo com os relatos, as pistas da linguagem não eram tão explícitas e o conhecimento prévio defasado, pois os estudantes desconheciam vocábulos da língua materna.

Portanto, a dificuldade de compreensão dos sentidos das palavras que ocasionaram problemas de assimilação da leitura, mencionada pelos entrevistados, reflete a não interatividade dos estudantes nos processos sócio culturais das comunidades em que estão inseridos ou a não utilização dos conhecimentos prévios destes indivíduos pelos professores, pois o problema existe e a realidade educativa foi mencionada pelos entrevistados. 


\section{2 SIGNIFICADO E IMPORTÂNCIA DA LEITURA}

Os PCNs postulam que a leitura é um processo no qual o leitor realiza um trabalho ativo de compreensão e interpretação do texto, a partir de seus objetivos e conhecimentos. Não se trata de extrair informação, decodificar letra por letra, palavra por palavra. Trata-se de uma atividade que implica estratégias de seleção, antecipação, inferência e verificação, sem as quais não ocorre proficiência. É o uso desses procedimentos que possibilita controlar o que é lido, permite tomar decisões diante de dificuldades de compreensão (BRASIL, 1998).

Por meio da leitura o estudante poderá se motivar a superar as barreiras da falta de discernimento e de relacionamento e levá-lo, progressivamente, à aquisição da habilidade de compreensão, com ganhos significativos no modo de pensar e de agir nesta atual realidade competitiva em que se encontra a sociedade (CASTRO, 2008).

O pensamento não se expressa apenas em palavras, ele se torna presente por meio delas e cria assim alicerces que geram compreensão de um texto. Logo, a leitura reflete o pensamento de um autor que interage com o leitor e os conhecimentos se relacionam e formarão um novo conhecimento desta interação de informações (VIGOTSKY, 1998).

A leitura ultrapassa a simples decodificação, pois para se compreender um texto, é preciso que o leitor faça uma adaptação dos procedimentos cognitivos como à atenção, a retenção, a evocação, a integração, a previsão, a comparação e raciocínio às características do texto, com o intuito de reconstruir o significado, segundo seus objetivos (CASTRO, 2008).

$\mathrm{O}$ ato de ler deve considerar também a enunciação, os aspectos contextuais envolvidos na leitura. Assim, reconhecer os gêneros textuais, utilizar estratégias adequadas de leitura e buscar informações condizentes com o que se pretende assimilar de conhecimento fazem parte de eventos de letramento que deveriam estar presentes nas aulas de leitura, assim os resultados poderiam ser significativos aos indivíduos (SCORSOLINI-COMIN; SANTOS, 20I0).

A concepção de leitura sociointeracionista considera a interação social como necessária para o processo de construção do conhecimento. Conjugada a essa visão e à 
noção proposta pelos modos de compreensão, a leitura se desenvolve como um ato comunicativo que envolve aspectos sociais, psicossociais e contextuais. Ler é obter informações advindas da leitura de mundo do leitor e do contexto no qual essa interação ocorre (VIGOTSKY, 1998).

Os dados coletados sinalizaram que entrevistados mencionaram sobre a importância e o significado que a leitura e citaram textos atuais com assuntos do cotidiano como os preferidos e relataram também que o conhecimento adquirido nas leituras servirá de base para o desenvolvimento pessoal de cada indivíduo.

Quadro 2 - Situações indicadas pelos alunos sobre o significado e importância da leitura

\begin{tabular}{|c|c|c|c|}
\hline Categoria molar & Categoria molecular & \multirow{2}{*}{$\begin{array}{l}\text { Unidade de registro } \\
\text { "“gosto de temas atuais, como } \\
\text { globalização, aquecimento global, } \\
\text { assim, temas que estão em evidencia." }\end{array}$} & \multirow{4}{*}{55} \\
\hline \multirow{6}{*}{$\begin{array}{l}\text { SIGNIFICADO } \\
\text { E IMPORTÂNCIA } \\
\text { DA LEITURA }\end{array}$} & \multirow{3}{*}{$\begin{array}{l}\text { LEITURA DE } \\
\text { TEMAS ATUAIS }\end{array}$} & & \\
\hline & & $\begin{array}{l}\text {-"gosto muito de ler coisas atuais } \\
\text { sobre temas globalizados, o que está } \\
\text { acontecendo no mundo atual." }\end{array}$ & \\
\hline & & $\begin{array}{l}\text {-"Aquela que retrata o dia- a- dia da } \\
\text { população com temas atualizados." }\end{array}$ & \\
\hline & $\begin{array}{l}\text { LEITURA COMO } \\
\text { APRENDIZADO } \\
\text { PARA A VIDA }\end{array}$ & $\begin{array}{l}\text {-"Eu leio num texto aquilo vai ter um } \\
\text { significado para mim. Vai dar uma } \\
\text { oportunidade para mim." }\end{array}$ & \\
\hline & & $\begin{array}{l}\text {-"Com a leitura agente aprende para a } \\
\text { vida" }\end{array}$ & \\
\hline & & $\begin{array}{l}\text {-"Porque a leitura hoje em dia é } \\
\text { essencial para a nossa vida." }\end{array}$ & \\
\hline
\end{tabular}

Em relação à categoria molecular que menciona a importância da leitura que produz significado se dá quando são trabalhados textos com temas atualizados. Neste sentido, Bassarewan e Silvestre (2010) relata que, nesta era globalizada, a leitura é um elemento importante para a vida do ser humano, uma vez que permite interagir com o outro e relacionar-se com saberem múltiplos e relevantes. Desenvolve a capacidade de compreensão, de questionamento e de interação com as invenções e saberes do mundo. Logo, os temas atualizados são importantes para que o indivíduo acompanhe as inovações que a nova realidade oferece. 
Ler é questionar o que está escrito num texto. Esta prática envolve uma expectativa real que vai da necessidade ao prazer numa autêntica situação de vida. Questionar um texto é formular hipóteses de sentido a partir de indícios anteriormente levantados. Este questionamento desenvolve-se por meio de uma estratégia de leitura que perpassa diretamente pelas situações de vida que o indivíduo já passou (BASSAREWAN; SILVESTRE, 20I0).

Por isso, os temas atuais mencionados pelos entrevistados como importante no ensino e aprendizagem da leitura, tornam-se interessantes, pois relatam situações do cotidiano universal onde os principais eventos da sociedade acontecem e são conhecidos e reconhecidos por estes sujeitos, logo, serão atrativos e bem conceituados pelos estudantes.

Ao adentrar-se nos conhecimentos de um texto o leitor expande conhecimentos e participa da transformação cultural do ambiente contido na literatura que interage. Logo, o ato de ler, situação marcada pela trajetória de vida do sujeito-leitor, deve ser uma ferramenta essencial no campo educacional, pois a educação oferece instrumentos que possibilitam o exercício da liberdade do homem para estruturar o seu projeto de existência, a fim de que tenha condições de interagir com sua própria cultura (SILVA, 2004).

VIGOTSKY (1989) estabelece uma importante distinção entre significado e sentido, pois aquilo que é convencionalmente estabelecido pelo social é o significado do signo linguístico; já o sentido é o signo interpretado pelo sujeito histórico, dentro de seu tempo, espaço e contexto de vida pessoal e social. Portanto, o significado do conhecimento promovido pela leitura de um texto deve ser relevante ao leitor, pois deve compor com os conhecimentos já adquiridos no decorrer das relações sociais.

A busca pela informação e pelo conhecimento no novo contexto social tem sido um processo constante, logo a leitura passou a ser um importante instrumento de aprendizagem. Dessa forma, possibilita a assimilação dos valores da sociedade e contribui para a formação de indivíduos ativos, pois por meio dela o indivíduo constrói novas percepções a respeito do mundo em que se relaciona e busca meios de conviver com as diferenças (SUEHIRO, 2008). 
A categoria molecular que menciona que a leitura é importante e que produz significado é aquela, segundo os relatos dos entrevistados, em que os textos trabalhados em sala de aula contribuem para o desenvolvimento pessoal do indivíduo.

No que se refere ao processo de leitura, deve-se compreender de que maneira o leitor, o escritor e o texto contribuem para a formação de um novo conhecimento, uma vez que a leitura implica numa ligação entre ambos. Assim, as características do leitor são tão importantes para a leitura como as características do texto, sendo que a capacidade de um leitor em particular é obviamente fundamental para o sucesso do processo. Vale ressaltar que o propósito do leitor, a cultura social, o conhecimento prévio, o controle linguístico, as atitudes, os esquemas conceituais, as habilidades e competências em geral são essenciais ao êxito no procedimento de ensino e aprendizagem da leitura (CUNHA; SANTOS, 2006).

Ler é compreender. A decifração é um componente e uma competência significativa do processo de leitura, mas só lê quem atribui significado àquilo que decifra, ou seja, quem compreende. O leitor tem um papel fundamental no processo de leitura, pois constrói significados para o que lê a partir do que o texto oferece, quando intervêm na construção de significados com os próprios conhecimentos e aprendizagens informais (SOARES, 2005).

A leitura é um processo cada vez mais presente no dia a dia do ser humano e possibilita a inserção social. Ela envolve praticamente quase todos os aspectos da psicologia humana como a capacidade sensorial, percepção, aprendizagem, motivação, pensamento, memória, dentre outros. Logo, as possibilidades de abstração da leitura compõem o dinamismo que envolve este processo de conhecimento (CANTALICE; OLIVEIRA, 2009).

$\mathrm{O}$ ato de ler não finaliza na simples decodificação da palavra ou da linguagem escrita. Ele antecipa e consegue se estender na inteligência do mundo, pois a leitura do mundo precede a leitura da palavra e esta implica na continuação do conhecimento universal. Este processo de movimento do mundo à palavra e da palavra ao mundo deve estar presente no ensino e aprendizagem da leitura, pois as informações que serão 
apreendidas num texto por meio do ato de ler devem contribuir para a formação do indivíduo (FREIRE, 1985).

VIGOTSKY (1989) salienta que as possibilidades ambientais proporcionam ao indivíduo que se constitua como sujeito lúcido e consciente capaz de induzir as situações relacionais em que vive. Neste sentido, o acesso a instrumentos físicos ou simbólicos desenvolvidos em gerações precedentes é fundamental, pois a viabilidade de manipulação destes utensílios promoverá ganhos significativos no desenvolvimento pessoal do indivíduo.

Portanto, ampliar o sentido do texto e não se deter apenas na leitura de superfície, precisa de exposição a situações diversas de prática que possibilitem ao indivíduo não apenas reproduzir o sentido do texto, mas refletir, dar opinião sobre o que lê e começar a entender os usos e as funções da leitura no mundo. A leitura se torna importante quando consegue transferir ao leitor conhecimentos que emitem significado para a vida, pois a importância está nas informações que despertam interesse e podem ser utilizadas no dia a dia como reconstrução dos saberes essenciais para a manutenção dos relacionamentos sociais.

\section{3 DISCUSSÕES}

A compreensão implica em traduzir palavras em conhecimentos. Logo, para compreender um texto é necessário construir significados por meio do entendimento das relações entre os enunciados e as informações contidas neles, pois para se fazer inferências é necessário que se reconheça, selecione informações relevantes e acione os conhecimentos de mundo para então estabelecer a compreensão textual (BORUCHOVITCH, 2009).

Um indivíduo com proficiência em leitura deve possuir habilidades concernentes à compreensão do texto em consonância com o contexto social em que este foi construído, pois quando o leitor é capaz de abstrair os significados explícitos e implícitos, num corpo textual, terá condições de interagir a leitura de palavras com a leitura de mundo (OLIVEIRA; BORUCHOVITCH; SANTOS, 2009). 
A história social e a pessoal nas quais o indivíduo se desenvolve podem determinar sua forma de pensar. Neste processo de desenvolvimento cognitivo, a linguagem tem papel fundamental na forma como a pessoa vai aprender a pensar, uma vez que formatos avançados de pensamento são repassados aos estudantes por meio de palavras (MOUSINHO, 2008). Logo, entende-se que a história de vida de cada pessoa é fundamental para que possua conhecimentos prévios que possam ser utilizados no processo de ensino e aprendizagem.

O problema de aprendizagem na leitura é uma condição que pode se prolongar por toda a vida, e causar impacto no desenvolvimento do indivíduo. Esta situação vai depender de fatores sociais, emocionais e educacionais e das funções ocupacionais, que por sua vez dependem das circunstâncias diárias, das relações interpessoais, do domínio de habilidades e de dificuldades individuais (SILVA; CAPELLINI, 2oII).

O que se percebeu com o descrito sobre a dificuldade de compreensão do significado das palavras, mencionados nos relatos dos sujeitos, é que a maioria pode ter tido problema de interação social, pois as relações interpessoais são meios que podem favorecer ou não o processo de ensino e aprendizagem na vida escolar do indivíduo.

Atualmente, no Brasil, presenciam-se problemas relacionados à Educação da rede pública de ensino. Dentre eles, têm-se o abandono escolar, a repetência por falta de alfabetização, queixas dos professores em relação à falta de concentração dos alunos, desinteresse, violência e indisciplina que corroboram com os problemas de aprendizagem (MAZER; BELLO; BAZON, 2009). Logo, segundo os pesquisadores a falta de concentração está pontuada como um dos problemas que dificultam o ensino $e$ aprendizagem na sala de aula.

O que se pontua, de acordo com o que se percebeu nas turmas que participaram da pesquisa é que a falta de concentração é motivada pelos ruídos promovidos por outros estudantes tanto os da própria sala quanto os que transladam pelos corredores, mas a principal causa ainda é o desconhecimento de vocabulários complexos utilizados em textos descontextualizados que ocasionam o desconforto da falta de concentração. 
As dificuldades de aprendizagem podem ser apresentadas ou percebidas no momento do ingresso formal do estudante na escola. Ressalta-se que este é um período de crucial importância para o desenvolvimento do indivíduo, pois este vem para adquirir competências nas relações interpessoais, sair-se bem na escola, aprender a ler e a escrever, e também, aprender a conviver num ambiente comunitário no qual as pessoas interagem uns com os outros (MAZER; BELLO; BAZON, 2009).

Logo, o que se entendeu com a reação de estudantes que participaram desta pesquisa e que não alcançaram desenvolvimentos educacionais previstos para o nível que estudam, é que não possuem habilidades suficientes que são exigidas na série que cursam. Logo, compreendeu-se que existem problemas de aprendizagens manifestados pelos indivíduos como dificuldade de compreensão do sentido das palavras e falta de concentração para a apreensão de conhecimentos textuais.

\section{CONSIDERAÇÕES FINAIS}

A importância da avaliação da aprendizagem tanto no processo quanto nos

resultados da prática de ensino deve ser considerada no momento da capacitação de educadores. No que condiz a leitura para a compreensão textual, procedimentos e instrumentos auxiliam no desenvolvimento das habilidades requeridas. Neste estudo foi utilizado um instrumento que possibilitou análise semântico-temática sobre a percepção de estudantes do terceiro ano do ensino médio de escolas públicas no que diz respeito à compreensão leitora.

Logo, para se entender os motivos, na ótica do estudante, que contribuem para o surgimento de dificuldades de compreensão na leitura de um texto e levam os estudantes a terem problemas de assimilação da leitura, foi utilizada a entrevista semiestruturada para a coleta de dados.

Um dos motivos citados pelos sujeitos foi à utilização de textos com palavras complexas utilizadas pelos educadores nas atividades de ensino de leitura que causa desconforto. O que se compreendeu é que textos com vocábulos desconhecidos não despertam interesse para o aprendizado do conhecimento. Esta atitude demonstra a falta 
de sintonia entre o professor e os alunos, pois ambos não interagem suas expectativas na sala de aula.

Entendeu-se também que esta prática educativa não considera o conhecimento trazido pelos estudantes de seus ambientes sociais, pois se trata de um ensino descontextualizado que acarreta desinteresse. Logo, desperta sentimento de repulsa às informações ora repassadas no ato de ensinar.

Em consequência deste motivo surgiu outro que possui relação de causa, pois foi citada a falta de concentração ocasionada por ruídos dentro e fora da sala de aula. Percebeu-se que a perturbação produzida por barulhos que desviam a atenção, na verdade configura-se num pretexto para as dificuldades de entendimento das palavras difíceis, ou seja, o desconhecimento de palavras é que causam o desconforto e tiram a atenção da leitura textual.

Os estudantes, também, pontuaram expectativas concernentes à importância e significado da leitura e, foi relatado que consideram as leituras com temáticas atualizadas, atrativas e importantes para a formação do indivíduo social, pois os conhecimentos são requeridos quando repassam significado para a vida.

As leituras atuais retratam o cotidiano das pessoas, com informações recentes de assuntos dos que pertencem ao ambiente de convívio, logo, despertam interesse de estudantes. Neste sentido, atividades de leitura com a utilização de textos atualizados podem configurar práticas atrativas com resultados significativos ao ensino $e$ aprendizagem da leitura, pois assuntos que pertencem ao mundo dos leitores são considerados confiáveis para se abstrair.

A importância da leitura, segundo os relatos, também foi medida pelos participantes quando são trabalhados textos que contenham conteúdos que repassam conhecimentos à vida em sociedade do indivíduo, pois para serem importantes, os assuntos devem trazer significado ao cidadão para que este possa estabelecer relações confiáveis com seus semelhantes.

Percebeu-se que estudantes possuem expectativa de vida no que condiz a aprendizados que contribuam para o convívio em sociedade, para o alcance de meios que os 
favoreçam ao crescimento pessoal. Logo, foram percebidos objetivos de vida que estes indivíduos possuem, pois esperam ser preparados, por meio dos conhecimentos oferecidos na prática da leitura de textos, ao convívio social.

As dificuldades que englobam a não compreensão de textos e os motivos na ótica dos estudantes configuram problemas no processo de ensino e aprendizagem. Por conta disso, os resultados dos institutos que fazem as avaliações do ensino na educação básica mostram que esta situação causa desconforto tanto para os professores quanto para os estudantes, pois ambos se sentem desconectados do sistema que rege o processo educativo de nosso país.

Neste sentido, acredita-se que as pesquisas relacionadas à área da psicologia e da educação podem conformar alternativas para amenizar este problema, pois é uma situação que provem de épocas passadas e que insiste em manter-se na atualidade, mesmo com os avanços tecnológicos que hoje é uma realidade palpável para as pessoas.

Abstraiu-se dos dados coletados conteúdos importantes para se repensar o processo de ensino e aprendizagem em turmas do último ano do ensino médio de escolas públicas, pois segundo os participantes da pesquisa as temáticas trabalhadas em sala de aula não traduzem a realidade dos alunos, logo, não são consideradas importantes.

Logo, espera-se que estes estudos provenientes da pesquisa sobre a compreensão leitora em alunos do terceiro ano do ensino médio de escolas públicas possam servir de subsídios para estudos posteriores e que estes conhecimentos também possam configurar elementos para que se procure amenizar este problema na educação brasileira que é a falta de compreensão de leitura.

\section{REFERÊNCIA BIBLIOGRÁFICA}

BAKHTIN, M. Língua, fala e enunciação. Tradução: Michel Lahud e Yara Frateschi Vieira. São Paulo: Hucitec, 1995.

BARDIN, Laurence. Análise de Conteúdo. Edição 70 revista e atualizada. Lisboa: março de 2009 . 
BASSAREWAN, Aicha. Binte. Umar; SILVESTRE, Simone. Michelle. O ensino e a aprendizagem da leitura nos primeiros anos da escolaridade em Timor-Leste. Educação e Pesquisa, v. 36, n. 2, São Paulo, 2010.

BORUCHOVITCH, E.A motivação do aluno. $4^{\underline{a}}$ Ed. Rio de Janeiro: editora Vozes, 2009.

BRASIL. Lei de Diretrizes e Bases da Educação Nacional no 9.394/96. Brasília: MEC, 1998.

BRASIL. Ministério da Educação. Instituto Nacional de Estudos e Pesquisas Educacionais Anísio Teixeira - INEP. Dados estatísticos da prova Brasil - 2009. Disponível em: www.inep.gov.br.

CANTALICE, Lucicleide Maria de; OLIVEIRA, Katya Luciane de. Estratégias de leitura e compreensão textual em universitários. Psicol. esc. educ., Campinas, v. 13, n. 2, dez. 2009. Disponível em: http://pepsic.bvsalud.org/scielo.php?script=sci_arttext\&pid.

CASTRO, A. C.M. Regina. Compreensão da leitura: aplicação da técnica do procedimento close nos ensinos fundamental e médio. Crátilo: Revista de Estudos Linguísticos e Literários. Patos de Minas: UNIPAM, (I): 70-78, ano I, 2008.

CEZAR COOL, et al, O construtivismo na sala de aula. Trad. Cláudia Schiling; 6. ed. São Paulo: Ática, 2009.

CUNHA, Neide de Brito; SANTOS, Acácia A. Angeli dos. Relação entre a compreensão da leitura e a produção escrita em universitários. Psicologia e Reflexão Crítica, Porto Alegre, v. 19, n. 2, 2006.

CABRAL, Álvaro. Dicionário Técnico de Psicologia, i4 ed. São Paulo: Cultrix, 2006.

DOCKRELL, Julie. Crianças com dificuldade de aprendizagem: uma abordagem cognitiva. Tradução Andrea Negreda. Porto Alegre: Artimed, 2000.

FREIRE, Paulo. Educação como prática para a liberdade. 17. Ed., Rio de Janeiro: Paz e Terra, 1985 .

FLICK, U. Uma introdução à pesquisa qualitativa. Porto Alegre: Bookman Companhia, 2006.

GERHARDT, Ana Flávia Lopes Magela; ALBUQUERQUE, Camila de Faro de; SILVA, Igor de Souza. A cognição situada e o conhecimento prévio em leitura e ensino. Ciência e Cognição. Rio de Janeiro, v. I4, n. 2, jul. 2009. Disponível em: http://pepsic.bvsalud.org/scielo.php?script=sci_arttext\&pid. 
LEFFA, Vilson Jose. Fatores da compreensão na leitura. In: Cadernos do IL. Porto Alegre, v.15, n.15, p.143-159, 1996.

MARTINS, João Carlos. Vigotsky e o papel das interações sociais na sala de aula: reconhecer e desvendar o mundo. 2009. 22I f. Tese (Doutorado em psicologia), Universidade Católica - PUC, São Paulo, 2009.

MAZER, Sheila Maria; BELlO, Alessandra Cristina Dal; BAZON, Marina Rezende. Dificuldades de aprendizagem: revisão de literatura sobre os fatores de risco associados. Psicologia e Educação, São Paulo, n. 28, jun. 2009 . Disponível em: http://pepsic.bvsalud.org/scielo.php?script=sci_arttext\&pid.

MOUSINHO, Renata et al. Aquisição e desenvolvimento da linguagem: dificuldades que podem surgir neste percurso. Rev. psicopedag., São Paulo, v. 25, n. 78, 2008. Disponível em: http://pepsic.bvsalud.org/scielo.php?script=sci_arttext\&pid.

NASCIMENTO, Tânia Augusto et al . Fluência e compreensão leitora em escolares com dificuldades de leitura.J. Soc. Bras. Fonoaudiologia. São Paulo, v. 23, n. 4, Dec. 2011. Disponível em:http://www.scielo.br/scielo.php?script=sci_arttext\&pid.

NOGUEIRA, Cláudio Marques Martins; NOGUEIRA, Maria Alice. A sociologia da educação de Pierre Bourdieu: limites e contribuições. Educação e Sociologia Campinas, v. 23, n.78, Abril,. 2002. Disponível em: http://www.scielo.br/scielo.php?script=sci_arttext\&pid.

OLIVEIRA, K. L., BORUCHOVITCH, E. \& SANTOS, A. A. A. Compreensão de leitura em alunos de sétima e oitava séries do Ensino Fundamental. In: revista semestral da Associação Brasileira de Psicologia Escolar e Educacional. Volume III, n. I janeiro/julho, 2007.

OLIVEIRA, Katya. Luciane de. Considerações acerca da compreensão em leitura no ensino superior.Psicologia ciência e professor, Brasília, v. 3I, n. 4, 20Ir. Disponível em: http://www.scielo.br/scielo.php?script=sci_arttext\&pid.

SANTOS, A. A. A. Compreensão de leitura na universidade: um estudo comparativo entre dois procedimentos de treino. Estudos de Psicologia, 7 (2), p. 39-53, 1990.

SANTOS, E.C.P. Compreensão de leitura: aplicação da técnica de Cloze em estudantes universitários. Intellectus - Revista Acadêmica das Faculdades Unopec. p. 58-81, 2005.

SCORSOLINI-COMIN, Fabio; SANTOS, Manoel Antônio dos. Bakhtin e os processos de desenvolvimento humano. Rev. bras. crescimento desenvolvimento humano. São Paulo, v. 20, n. $\quad$ 3, 2010. $\quad$ Disponível em:http://www.revistasusp.sibi.usp.br/scielo.php?script=sci_arttext\&pid. 
SILVA, Maria do Pilar Cunha. Os modos de compreensão e a leitura na escola. Dissertação de mestrado.Universidade Estadual de Campinas/Faculdade de Educação, Campinas,1998.

SILVA, V. R. Estratégias de leitura e competência leitora: contribuições para a prática de leitura em história. História, 23 (I-2), p. 69-83, São Paulo: Cortez, 2004.

SILVA, M. Sala de aula interativa. São Paulo: edições Loyola, 2010.

SILVA, Cláudia; CAPELLINI, Simone Aparecida. Desempenho cognitivo-linguístico de escolares com distúrbio de aprendizagem.Psicol.estud., Maringá, v. ı6, n. I, Mar. 20Ir.Disponível em: http://www.scielo.br/scielo.php?script=sci_arttext\&pid.

SOARES, M. As condições sociais da leitura: uma reflexão em contraponto. São Paulo: Ática, 2005.

SUEHIRO, Adriana Cristina Boulhoça. Processos fonológicos e perceptuais e aprendizagem da leitura e escrita: instrumentos de avaliação. 2004. $240 \mathrm{f}$. Tese (doutorado em Psicologia), Universidade São Francisco, Itatiba, 2008.

VIGOTSKY, Lev. S. Linguagem, desenvolvimento e aprendizagem. São Paulo: Ícone, 1988.

A formação social da mente. São Paulo: Martins Fontes, 1989.

O pensamento e a linguagem. São Paulo: Martins Fontes, 1998.

A construção do pensamento e da linguagem. São Paulo: Martins Fontes,

2001.

ZUCOLOTO, Karla Aparecida. A compreensão da leitura em crianças com dificuldades de aprendizagem na escrita. 200I. I45 f. Dissertação (Mestrado em Educação), Faculdade de Educação, Universidade Estadual de Campinas, Campinas 2oor. 